\title{
Xenohybrid Bone graft Containing Intrinsically Disordered Proteins (IDP) Shows Enhanced in vitro Bone Formation
}

Hao Zhu', ${ }^{1,2}$, Manuel Gomez ${ }^{2 \dagger}$, Jun Xiao ${ }^{1 *}$, Giuseppe Perale ${ }^{3,4,5}$, Felice Betge ${ }^{3}$, Ståle Petter Lyngstadaas $^{2}$, Håvard Jostein Haugen ${ }^{*}$

${ }^{1}$ Department of Orthopedic Surgery, Tongji Hospital, Tongji Medical College, Huazhong University of Science and Technology, 1095 Jiefang Avenue, Wuhan 430030, China

${ }^{2}$ Corticalis AS, Oslo Sciencepark, Gaustadallén 21, NO- 0349 Oslo, Norway

${ }^{3}$ Industrie Biomediche Insubri SA, Via Cantonale 67, 6805 Mezzovico-Vira, Switzerland

${ }^{4}$ Faculty of Biomedical Sciences, University of Southern Switzerland, Via G. Buffi 13, 6900 Lugano, Switzerland

${ }^{5}$ Ludwig Boltzmann Institute for Experimental and Clinical Traumatology, Donaueschingenstrasse 13, 1200 Vienna, Austria

†Present address: 3B's Research Group, I3B's - Research Institute on Biomaterials, Biodegradables and Biomimetics, University of Minho, Guimarães, Portugal.

\section{Corresponding authors:}

Jun Xiao, Department of Orthopedic Surgery, Tongji Hospital, Tongji Medical College, Huazhong University of Science and Technology, 1095 Jiefang Avenue, Wuhan 430030, China. Phone: +86-83665318 Fax: +86-83665318 Email: jun_xiao@hust.edu.cn

Håvard Jostein Haugen, Corticalis AS, Oslo Sciencepark, Gaustadallén 21, NO- 0349 Oslo, Norway Phone: + +47 22958500 Email: haugen@corticalis.com 


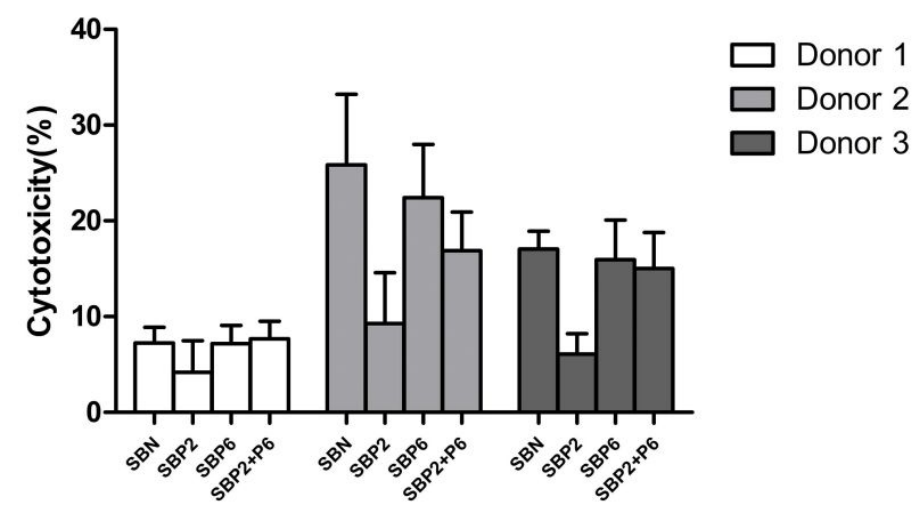

Figure S1. Cytotoxicity of SBP. 
Donor 1

oc
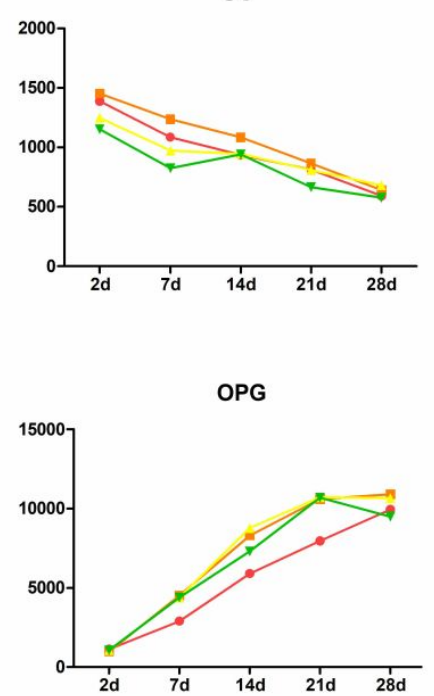

OPN

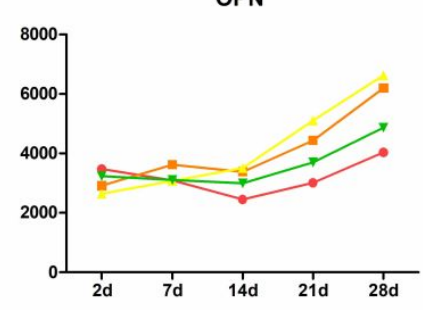

DKK-1

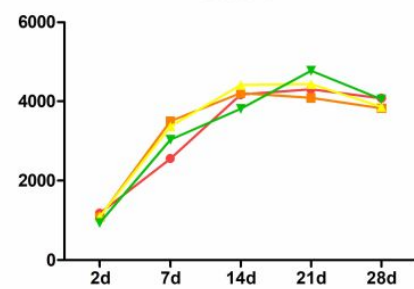

SOST

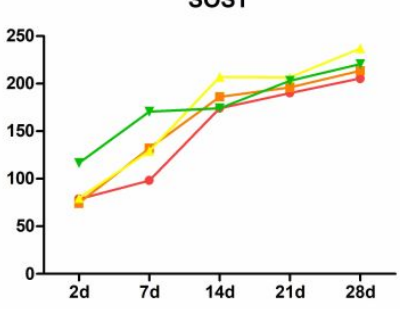

Donor 2

OC

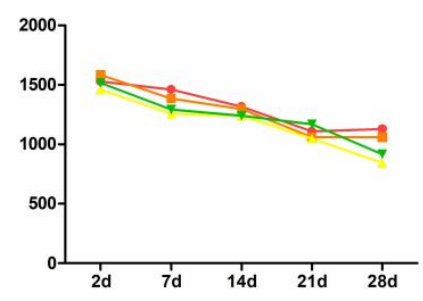

OPG

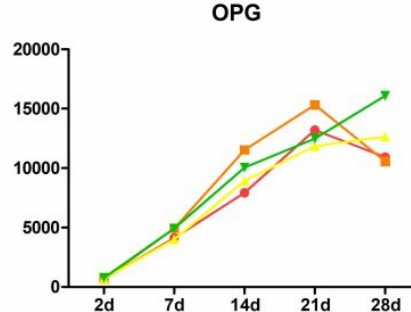

OPN

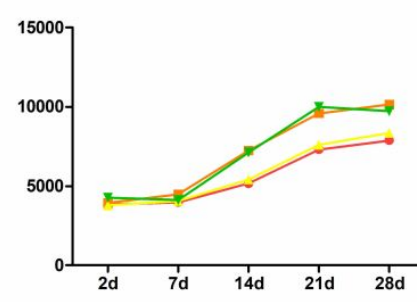

DKK-1

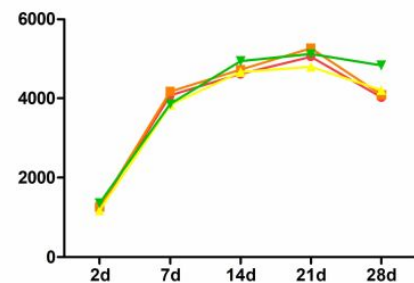

SOST

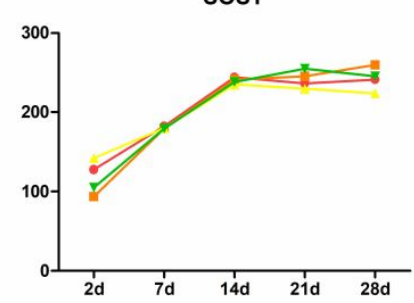

Donor 3

oc

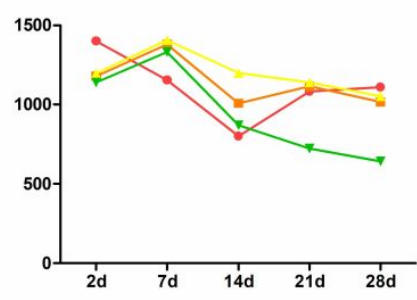

OPG

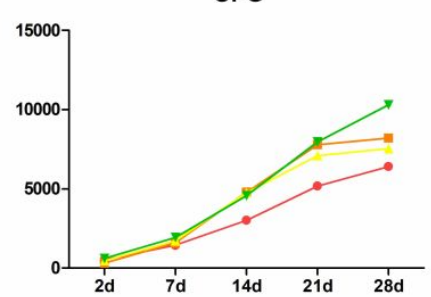

OPN

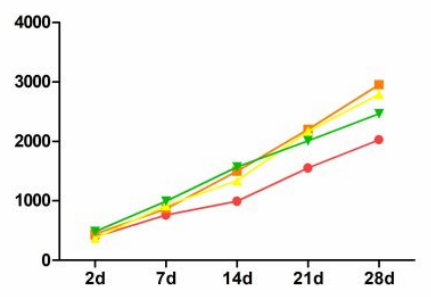

DKK-1

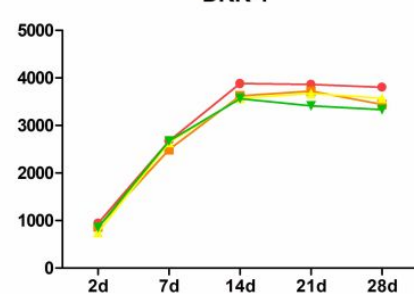

SOST

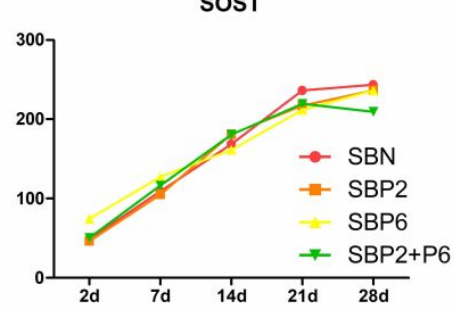


Figure S2. The quantification results of specific protein secretion. Results were shown as lines. 